\title{
Adversidades, disputas e gargalos na difusão de computadores no Brasil: A inserção da Administração Pública e do setor privado na constituição de um mercado brasileiro de tecnologia da informação. (1957 - 1964).
}

Lucas de Almeida Pereira* Maria Gabriela da Silva Martins Cunha Marinho**

Resumo: A crescente informatização das sociedades contemporâneas tem sido objeto de análises que contemplam dimensões tecnológicas, econômicas, políticas, filosóficas, cognitivas, entre outros aspectos. Contudo, no caso brasileiro, um traço ainda negligenciado desse processo é o que se refere à sua perspectiva histórica, especialmente no que tange às interações entre os setores público e privado, seja em termos da aquisição, instalação e manutenção de maquinário, sejam na dimensão desses atores como usuários, ou até mesmo as condições gerais de infraestrutura física do país. O artigo propõe uma análise em torno das condições históricas que assistiram, no começo da década de 1960, a inserção crescente do Brasil no mercado da tecnologia da informação. Nesse sentido, aponta para a diversidade de atores, públicos e privados, que atuaram em diferentes nichos e níveis de disputa, resultando em um processo de múltiplas variáveis.

Palavras-Chave: História da informática; políticas públicas; Tecnologia da informação.

Abstract: The increasing informatization of contemporary societies has been the subject of analyzes that include technological economic, political, philosophical, cognitive dimensions, and so on. However, in Brazil, a trait still neglected in this process is the relation with its historical perspective, especially with regard to the interactions between the public and private sectors, in terms of the acquisition, installation and maintenance of machinery, wheter the dimension of these actors as users, or even the general conditions of physical infrastructure of the country. The paper presents an analysis around the historical conditions that attended, in the early 1960s, the growing role of Brazil in the market of information technology. In this

\footnotetext{
* Doutor em história pelo programa de Pós-Graduação da UNESP Assis (2013) realiza atualmente estágio de Pós-doutorado no Programa de Pós-Graduação em Ciências Humanas e Sociais da Universidade Federal do ABC.

** Professora do Programa de Pós-Graduação em Ciências Humanas e Sociais da Universidade Federal do $\mathrm{ABC}$.
} 
sense, points to the diversity of actors, public and private, who worked in different niches and dispute levels, resulting in a process of multiple variables.

Keywords: History of informatics; public policies; thecnology of information.

\section{Introdução}

Cenário de uma conjuntura política tensa e conturbada, com sequelas que seriam duramente processadas nas décadas subsequentes, os anos de 1960 representaram para o Brasil o início, também, de intenso ajuste às inovações tecnológicas que eram operadas a partir, sobretudo, do ambiente corporativo norteamericano em estreita articulação com o sistema de defesa daquele país. Nesse contexto, em que as contradições políticas se acentuavam igualmente no plano internacional, com o acirramento da chamada Guerra Fria, as disputas se desenrolavam também de maneira decisiva no campo científico e tecnológico. No caso brasileiro, um marco relevante e pouco analisado desta arena foi a entrada do país na área de processamento de dados.

As primeiras importações de computadores para o Censo do Instituto Brasileiro de Geografia e Estatística (IBGE), a partir de 1960, foram seguidas de um numero crescente de novos equipamentos encomendados junto a fornecedores internacionais que se encarregavam das instalações e do treinamento inicial. Restava, contudo, a operação subsequente e a interligação com os setores que demandantes dos novos serviços e atividades. Assim, estavam dadas as condições para a criação do mercado dos Centros de Processamento de Dados (CPD), que se consolidaria de modo consistente nos anos subsequentes, e por todo o país, em empresas públicas e privadas.

Acoplada aos CPDs, iria se desenvolver uma plêiade de novos profissionais e segmentos especializados na instalação, operação, manutenção e comercialização de equipamentos, programas, acessórios e periféricos para computadores, como leitoras de cartão e impressoras, além de manuais e bibliografias específicas que precisavam ser traduzidas e termos técnicos adaptados. Tratava-se, enfim, da emergência de uma cultura científica e tecnológica que exigiria também a criação de novos cursos para a formação de profissionais habilitados, já que a mão de obra neste período era constituída, basicamente, por técnicos treinados pelas empresas e jovens engenheiros recém-formados. 
De modo seletivo e localizado, ainda assim, algumas universidades e institutos de pesquisa brasileiros participaram, a partir de 1960, do contexto de instalação dessa nova cultura técnica e científica, caso do Instituto Tecnológico da Aeronáutica (ITA), do Instituto de Matemática e Engenharia (IME) e da Pontifícia Universidade Católica do Rio de Janeiro (PUC-RJ). Mais especificamente, a PUC-RJ titulou em 1962 sua primeira turma de engenharia eletrônica que teve efetivamente contato com os equipamentos importados.

Apesar das iniciativas em torno da qualificação profissional, ainda assim, a maior parte dos serviços de manutenção e instalação de computadores era realizada por técnicos da empresa vendedora, em geral com alguma experiência no exterior. Ao lado da escassez de informações e infraestrutura, inerentes para áreas em constituição, havia também a insatisfação salarial. Em meio à polêmica que se instalou em torno do mau funcionamento do UNIVAC 1005 a Remington Rand, em nota oficial, alertou que não bastava investir na manutenção do equipamento sem melhorar a remuneração dos técnicos:

Eles não podem ganhar, pela natureza e alta especialização do tipo de trabalho que executam, os salários baixos do funcionalismo publico brasileiros (...) técnicos mal pagos não podem ser bons técnicos e deles depende a vida futura do equipamento. (O GLOBO, 17/05/1961).

Ao lado dos salários, a estrutura física era outro "gargalo" em relação ao funcionamento adequado de equipamentos caros e delicados. São Paulo e Rio de Janeiro, as primeiras cidades brasileiras a terem computadores instalados, enfrentavam problemas graves de infraestrutura urbana, nos setores de telefonia, água, esgoto, energia elétrica. A chamada explosão urbana, em decorrência das migrações internas e da rápida industrialização, havia fragilizado ainda mais os sistemas de abastecimento e escoamento insuficientes para o crescimento acelerado da demanda.

No Sudeste, as chuvas de verão provocavam inundações catastróficas que afetavam a rede de transmissão, transformando em rotina os frequentes apagões que, em muitos casos, se tornaram programados. Porém, o reverso também era comum e, em 1964, São Paulo viveu uma longa estiagem que atingiu severamente os 
reservatórios das represas Billings e Guarapiranga. Em decorrência, a Light empresa fornecedora de energia da época - instituiu o "racionamento compulsório de energia elétrica" (FSP, 24/01/64, p.7) com a interrupção diária do fornecimento em horários e regiões programadas ${ }^{1}$. Para os computadores, as consequências foram arrasadoras. Em relação aos equipamentos de “primeira geração”, operando por meio de milhares de válvulas, a queda frequente da energia comprometia todo o sistema, encarecendo ainda mais a manutenção.

Desse modo, os custos elevados de manutenção somavam-se aos de importação, instalação, impostos, remuneração de técnicos, aquisição de peças restringiam o acesso aos equipamentos quase sempre às filiais das corporações multinacionais e a alguns setores da administração pública. Como lembra Peter Evans acerca da informatização brasileira, "The computer industry reflected the standard Brazilian division of labor in which technology-intensive industries were dominated by foreign capital" (EVANS, 1995 p.109). O esforço de capacitação para acompanhar o mercado restrito e intensamente disputado pelos grandes fornecedores, principalmente IBM, Burroughs e Remington Rand, constitui o cerne da análise desenvolvida a seguir.

\section{O uso de computadores na Administração Pública}

Em meados da década de 1960 os computadores, ao lado da energia nuclear, assumiram a dianteira na disputa pelas inovações tecnológicas que poderiam conferir hegemonia na corrida armamentista que dividia a União Soviética e os Estados Unidos. Esse período foi caracterizado por Philipe Breton como a transição da "primeira informática” para a segunda. O período da primeira informática ocorreu no ínterim entre 1950 e 1960 e foi marcado pela presença maciça do governo dos Estados Unidos "a existência de um mercado estatal nos Estados Unidos estará na raiz da expansão de uma indústria mais tarde voltada para o mercado civil” (BRETON, 1991, p. 205). A segunda fase, período no qual os computadores chegaram com força ao Brasil, foi caracterizada pela "tomada de consciência do lance

\footnotetext{
${ }^{1}$ No verão de 1964 a Companhia Light determinou apagões de meia hora no centro (entre as 9:30 e as 10:00 da manhã) em função da estiagem. Nos bairros a situação era pior: "Em vista disso, a Light determinou o racionamento compulsório de energia elétrica de 2 horas nos bairros da capital, no período entre 7:30 e 15:30, a fim de preservar as poucas reservas energéticas que ainda dispõe" (FSP, 24/01/1964 p.7).
} 
Revista Brasileira de História \& Ciências Sociais - RBHCS

Vol. $8 \mathrm{~N}^{\mathrm{o}}$ 16, Julho - Dezembro de 2016

estratégico constituído pela informação” (BRETON, 1991, p. 205), ou seja, por uma entrada contundente das grandes firmas estadunidenses no mercado internacional.

Na América Latina, o Brasil foi o principal comprador dos chamados "cérebros eletrônicos”, como ficaram conhecidos os primeiros computadores. No Cone Sul, a Argentina, em 1962, e o Chile, em 1964, se alinharam na disputa pela informatização, inicialmente se voltando apenas para a aquisição dos equipamentos. Mas o Brasil, além de comprar, buscava desenvolver massa crítica nas universidades. No início da década de 1960, o país começava a colher alguns resultados: a primeira geração de engenheiros elétricos estava deixando as salas da PUC-RJ, do ITA, em São José dos Campos, e da Escola Politécnica da Universidade de São Paulo², preparada para operar e programar computadores eletrônicos.

A nova geração de engenheiros enfrentaria, contudo, um conjunto de adversidades. Os computadores instalados no Brasil passavam, necessariamente, por um longo processo burocrático remanescente do Grupo Executivo para aplicação de Computadores Eletrônicos (GEACE), liderado pelo economista Roberto Campos. Embora o grupo tenha sido dissolvido após o fim do mandado de Kubistchek o modelo de incentivos e procedimentos para a aquisição de computadores eletrônicos manteve-se durante o governo seguinte, de João Goulart, que não demonstrou o mesmo entusiasmo com os cérebros eletrônicos.

O ambiente político e econômico era igualmente desanimador. Goulart chegara à presidência após a polêmica renúncia de Jânio Quadros com o país imerso em dívidas decorrentes do governo anterior, pressionado pela perseguição à Revolução Cubana e cercado por inúmeras críticas e investigações em torno da aquisição do computador do IBGE - o maior e mais caro modelo em operação no Brasil.

A primeira tentativa de se utilização dos computadores na administração federal aconteceu em janeiro de 1961. Pouco antes da posse de Jânio Quadros, Juscelino assinou o decreto $\mathrm{n}^{0} 49.914$ criando o Centro de Processamento de Dados do Governo (CPDG). Pelo decreto,3 o IBGE manteria a prioridade sobre o

\footnotetext{
2 A PUC-RJ foi a primeira universidade a contar com um computador (Burroughs B205), seguida pela Escola Politécnica de São Paulo, com um IBM 1620 (1962) e pelo ITA (1963) também com um IBM 1620.

3 Segue abaixo o artigo segundo do decreto que dispõe das finalidades do CPDG:

Art. $2^{\mathrm{o}}$. São finalidades principais do CPDG: I - efetuar as apurações censitárias e estatísticas e os cálculos geodésicos de interesse do Sistema Estatísticos-Geográfico Brasileiro; II - auxiliar o estudo e a
} 
equipamento UNIVAC 1005, cuja função primordial era executar serviços censitários. Porém, deveria compartilhar o uso com o governo federal e outras agências públicas, inclusive para pesquisas científicas.

Pelo decreto, o CPDG seria dirigido por um conselho executivo 4 formado por onze executivos de diversos órgãos que incluíam as Forças Armadas e o Conselho Nacional de Pesquisa (CNPq). Considerado estratégico, o primeiro centro de processamento adquiriu autonomia para requisitar servidores de outros órgãos públicos e contratar mão-de-obra pelo regime trabalhista, sem vínculos com o governo - sem necessidade, portanto, de concurso público. A autonomia era assegurada ainda pela existência de um fundo especial depositado no Banco do Brasil alimentado pela receita de serviços prestados e verbas orçamentárias. Até a regulamentação e pleno funcionamento do fundo, caberia ao IBGE arcar com os custos do CPDG, aspecto que resultaria em cisões internas, conforme analisado mais adiante.

A oposição ao modus operandi partiu do próprio IBGE. No contexto de transição da gestão, o novo diretor Rafael Xavier protestou, considerando o decreto lesivo ao instituto, já mergulhado em dívidas e investigações. Xavier solicitou a revogação, concedida por Jânio Quadros em março do mesmo ano, por meio do decreto $\mathrm{n}^{0}$ 50.371. O novo ato revogou a criação do CPDG e restituiu ao IBGE a exclusividade sobre o UNIVAC 1005 .

Com a revogação do decreto, a informatização da administração federal começou efetivamente a ser implantada apenas no final de 1962 com o objetivo de

solução dos problemas básicos essenciais às decisões do Governo; III - efetuar cálculos e processamento de dados necessários à solução de problemas singulares dos diversos órgãos do Governo; IV - disseminar e desenvolver novos métodos de processamento de dados;

$\mathrm{V}$ - formar e aperfeiçoar pessoal técnico destinado a propiciar o funcionamento de centros oficiais similares que se instalarem no país; e VI - auxiliar os estudos científicos das instituições oficiais de pesquisas, centros universitários, sociedades de economia mista e outras entidades.

4 Art. $3^{\circ}$. O CPDG será administrativo por um Conselho Diretor, presidido pelo Presidente do Instituto Brasileiro de Geografia e Estatística, integrado também por representantes dos seguintes órgãos designados pelos respectivos dirigentes: I - Estado Maior das Forças Armadas; II - Ministério da Educação e Cultura; III - Conselho Nacional de Estatística; IV - Conselho Nacional de Geografia; V - Conselho Nacional de Pesquisas; VI - Conselho do Desenvolvimento; VII - Escola Nacional de Ciências Estatísticas; VIII - Escola Nacional de Engenharia; IX - Comissão Nacional de Energia Nuclear; X - Centro Brasileiro de Pesquisas Físicas; XI - Serviço Nacional de Recenseamento.

5 Artigo segundo: O Instituto Brasileiro de Geografia e Estatística, por intermédio do seu colegiado dirigente, estabelecerá as normas indispensáveis para operar o Computador Eletrônico de Grande Porte Univac 1105, com vistas, em caráter prioritário, à apuração do Recenseamento Geral de 1960 (decreto $\mathrm{n}^{0}$ 50.371, de 22 de março de 1961). 
Revista Brasileira de História \& Ciências Sociais - RBHCS

Vol. $8 \mathrm{~N}^{\mathrm{O}}$ 16, Julho - Dezembro de 2016

melhorar a eficiência na arrecadação de tributos, especificamente para o Ministério da Fazenda visando o imposto de renda. Marcado uma vez mais por disputas dentro e fora do governo, e junto ao mercado fornecedor, as correntes adversárias seriam silenciadas, porém, com o advento do golpe militar em 1964.

\section{Marchas e Contramarchas: o papel da arrecadação de tributos}

A decisão do governo de assegurar maior eficiência à sua máquina de arrecadação foi anunciada pelo diretor da Divisão de Despesa Pública do Ministério da Fazenda, Luis Souza Pinto, em junho de 1962. Por meio de entrevista concedida o jornal Correio da Manhã, Souza Pinto apontava a necessidade de agilizar a arrecadação de impostos e de receitas previdenciárias. Para tanto, em torno de 60 dias a Divisão deveria receber um computador cuja missão seria mecanizar o processo de emissão e arrecadação das guias de imposto de renda. Instituído no Brasil em 1922 de forma experimental, esse tributo só foi regulamentado em 1924 quando o ministro Souza Reis, após avaliar os modelos de arrecadação de vários países optou por seguir os Estados Unidos que dividida seu território em regiões autônomas (Cf. MINISTÉRIO DA FAZENDA, 2010).

Menos de quinze anos após sua promulgação, o imposto de renda passou a responder pela terceira maior arrecadação tributária da União, atrás apenas dos impostos sobre consumo e do imposto sobre importações. Apesar do percentual relativamente baixo de declarações, até o início da Segunda Guerra, o imposto de renda havia aumentado de modo expressivo sua participação no orçamento da União, saltando de $3 \%$ para $8 \%$. Durante a Guerra o governo brasileiro lançou a Comissão de Reorganização dos Serviços da Diretoria do Imposto de Renda, de modo a reforçar a arrecadação, aumentar o caixa e financiar participação brasileira junto aos Aliados. O imposto de renda tornou-se atrelado a títulos de Obrigação de Guerra, cobrança compulsória instituída a empregados e empregadores.

Em função destas mudanças, "em cinco anos, o imposto de renda passou de 10\% para $28 \%$ no total da receita tributária federal e em 1943 alcançou um marco inédito: primeiro lugar em arrecadação. De 1944 até 1978 dividiu a liderança com o imposto de consumo" (MINISTÉRIO DA FAZENDA, 2010). O final da Guerra não 
alterou o quadro da arrecadação e o imposto de renda manteve-se como fonte prioritária das receitas federais, em função de fatores como: investimentos em maquinaria e pessoal no setor de cobranças; substituição do conto de réis pelo cruzeiro; aumento gradativo da base de contribuintes.

\section{Gráfico I - Evolução do número de declarações do imposto de renda (Página 7, segundo parágrafo).}

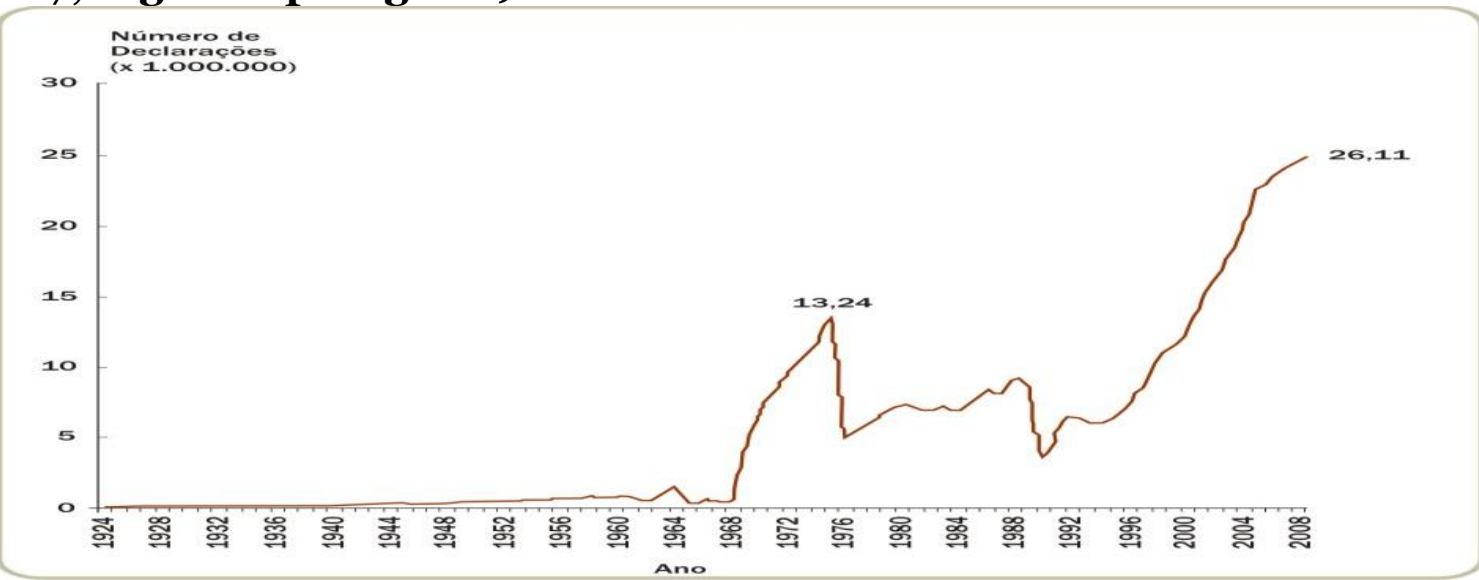

(Fonte: Relatórios da Delegacia Geral, da Diretoria, da Divisão e do Departamento do Imposto de Renda e sistemas gerenciais da SRF. Disponível em MINISTÉRIO DA FAZENDA, 2010).

Embora tenha se tornado rapidamente uma das principais fontes de arrecadação da União, no início da década de 1960 o sistema do imposto de renda estava novamente à beira de um colapso, dado o aumento de variáveis em sua operação. Em 1962, o Ministério da Fazenda tornou obrigatório, também, a declaração de bens, visando detectar casos de enriquecimento incompatível com a atividade exercida. No mesmo período, o imposto passou a incidir também sobre uma parcela maior da população como aponta o gráfico acima (variação positiva entre $61 \mathrm{e}$ 64, recuo entre 64 e 67 e explosão a partir de 1968).

Para assegurar a eficácia da nova regulamentação, abriu-se uma nova frente de disputas referente à aquisição dos equipamentos. A escolha da Remington Rand gerou críticas dos concorrentes do edital. Quatro empresas haviam se candidatado duas nacionais, ORGAMEC e SERVIMEC, e duas multinacionais, Remington Rand e $I B M$. Das quatro, duas desistiram - SERVIMEC e IBM não apresentaram proposta e a Remington venceu a ORGAMEC.

O edital previa a aquisição de um computador de grande porte para a delegacia de arrecadação de São Paulo e de máquinas simples para as demais delegacias, fornecimento que vinha sendo realizado pela Remington Rand (Cf. DOU, 
Revista Brasileira de História \& Ciências Sociais - RBHCS

Vol. $8 \mathrm{~N}^{\mathrm{o}}$ 16, Julho - Dezembro de 2016

18/10/1962, p.15). Na proposta da ORGAMEC, publicada no Diário Oficial, a empresa se apresentava como a maior do setor na área de processamento e mecanização de dados, com capital totalmente nacional. E acusava os organizadores da concorrência de favorecimento para as multinacionais: "Não julgamos agora possível que no Brasil (...) se promovam intencionalmente certas disposições em um edital de concorrência publica que venham eliminar empresas totalmente nacionais" (DOU, 18/10/1962, p.15).

Para os diretores da ORGAMEC, ao se fazer um edital único, destinado ao fornecimento de equipamentos e contratação de pessoal, criava-se um cenário insustentável para as empresas nacionais, obrigadas arcar, de uma só vez, com despesas que atingiriam quase 80 milhões de cruzeiros, algo em torno de $160 \mathrm{mil}$ dólares no câmbio da época ${ }^{6}$. Caso uma empresa nacional vencesse o edital, seria obrigada a desembolsar, de imediato, "uma importância aproximadamente de Cr\$ 80.000.00o para atender a taxas de instalação de equipamentos fabricados no estrangeiro, remoção de pessoal técnico para as devidas localidades de execução de serviço e caução de 10\%” (DOU, 18/10/1962, p.15).

As pressões não mudaram o resultado. A Remington se manteve como vencedora e o equipamento fornecido tornou-se obsoleto rapidamente, empurrando novamente o sistema para a crise seguinte. Assim, em despacho divulgado pelo jornal O Globo no início de 1964, o então ministro da Fazenda, Nei Galvão, alertava para a possibilidade de colapso no sistema de arrecadação do imposto de renda caso não se efetuasse a compra de quatro novos computadores.

Galvão argumentava que o aumento substancial de declarações ocorria nas principais cidades brasileiras, como São Paulo, Rio de Janeiro, Recife e Salvador, o que sobrecarregava o equipamento da Divisão de Imposto de Renda da Fazenda. O regime de urgência dessas aquisições justificaria a dispensa de licitação ou concorrência publica. Sugeria, portanto, a aquisição de quatro modelos específicos, no caso UNIVAC 1004/o7, com base em complicada engenharia financeira:

Tratando-se, no entanto, de aquisição de equipamentos para complementar os conjuntos já em funcionamento, e dado a exiguidade do tempo, necessário se torna autorização do Presidente

${ }^{6}$ Informação referente a setembro de 1962, mês no qual o dólar oscilou entre 495 e 515 cruzeiros o dólar. Disponível em Folha de São Paulo, 11/o9/1962, Primeiro Caderno, p.60. 
da Republica para que se efetue a compra com dispensa de concorrência, até os limites de 250 mil dólares, para pagamento pela delegacia do Tesouro Brasileiro no exterior e de $\operatorname{Cr} \$ 486$ milhões para pagamento no país. (NEI GALVÃO IN O GLOBO, 12/o3/1964, p6).

A petição do ministro incluía também a renovação do contrato de aluguel e manutenção dos equipamentos instalados pela Remington, produtora do UNIVAC. Assim, sob a justificativa de urgência, o ministro sugeria um grande contrato com a empresa Remington Rand, entre compras e renovações, sem a necessidade de se licitar o equipamento. Mas em meados de março de 1964 já não havia tempo para quase mais nada no governo Goulart em face ao golpe militar perpetrado no mês subsequente. Assim, no plano federal, os primeiros Centros de Processamento de Dados seriam criados apenas sob a vigência da ditadura militar, enquanto a automação da burocracia municipal e estadual tivera início no começo da década de 1960 com as iniciativas de São Paulo e do estado da Guanabara.

\section{Difusão em diferentes níveis e escalas da administração pública}

Os primeiros computadores destinados à administração pública, dois modelos IBM 1401, haviam sido comprados pela prefeitura da cidade de São Paulo em agosto de 1960. De maior porte que o RAMAC 305, o 1401 foi um dos computadores mais vendidos da primeira geração e em poucos anos se tornaria o computador mais instalado no país. O equipamento chegaria a São Paulo em dezembro de 1961, um ano após a aquisição. Sua principal função seria agilizar a emissão dos impostos municipais7, conforme declarou ao Correio da Manhã o secretário de finanças, Monteiro de Carvalho. Para ele, o computador determinaria "maior rapidez e eficiência no lançamento, arrecadação e cobrança da dívida ativa da Prefeitura e, inclusive, possibilitará a transformação dos arquivos da municipalidade em arquivos de fitas magnéticas" (CDM, 03/12/63, p.7).

\footnotetext{
7 "Assim, sucessivamente à medida que as programações forem sendo elaboradas, a municipalidade paulista passará a executar os seguintes serviços pelos mais novos métodos eletrônicos: 1- Emissão de impostos e taxas; 2- controle de arrecadação; 3- Emissão da dívida ativa; 4- controle de arrecadação da Dívida ativa; 5- Certidões negativas; 6- Folhas de pagamento do pessoal; 7- Contagem de tempo de serviço dos funcionários; 8- Controle de verbas e aplicações; 9- Controle de bens patrimoniais" (O GLOBO, 25/01/62, p.12).
} 
$\mathrm{Na}$ capital, os computadores seguiram para o Parque do Ibirapuera que abrigava diversos órgãos da administração. Porém, não havia ali a infraestrutura necessária, e a Prefeitura começou a operar o IBM 1401 na sede da própria IBM. Apesar da precariedade do processo, periódicos como O Globo destacavam o “pioneirismo paulista”. “Confirmando mais uma vez seu espírito de pioneirismo, São Paulo está marcando uma nova e revolucionária etapa na sua vida publica: a prefeitura da Capital acaba de receber dois computadores eletrônicos”. (O GLOBO, 25/01/62, p.12)

Embora inaugurados oficialmente em 1962, os computadores da Prefeitura demoraram a entrar em funcionamento. O primeiro começou a operar no início de 1964 e o segundo em outubro do mesmo ano, envoltos pela retórica triunfal, já que funcionavam "emitindo mais de 50 avisos de impostos por minuto e cerca de três mil por hora, o computador da Secretaria de Finanças da Prefeitura de SP está apto a expedir à hora e a tempo, os avisos para 1,2 milhões de contribuintes” (FSP, 15/02/1964).

O equipamento permitiria ainda ampliar a automação dos tributos: "O novo equipamento eletrônico ampliará a capacidade do serviço de lançamentos dos impostos de indústrias e profissões, predial e territorial, e emissão de cheques de pagamento ao funcionalismo municipal" (FOLHA DE SAO PAULO, 14/01/1964). O valor total pago para IBM, divulgado pelo jornal O Estado de São Paulo, foi de 240 milhões e 120 mil cruzeiros, além da contratação de maquinaria auxiliar (impressoras, periféricos etc.) por meio de aluguel ao custo mensal de 12 milhões e 951 mil cruzeiros.

Os computadores, que sequer haviam sido instalados no Ibirapuera, serviriam ainda na sede da IBM, para majorar em 14\% o imposto sobre veículos. Graças ao equipamento a prefeitura conseguiu atualizar a cobrança em tempo recorde, ao contrário do Estado que, sem maquinaria de porte, não conseguiu corrigir manualmente as cobranças. Ainda que destinado também ao planejamento, o uso computador permanecia atrelado à busca de receitas, como informava a imprensa da época. "Para controle do prefeito e do secretário das Finanças o computador executa um serviço que sem a sua interferência levaria meses para ser elaborado: a previsão das arrecadações futuras” (FSP, 15/02/1964). A insistência na modernização da arrecadação e o distanciamento dos serviços aos cidadãos foram ironizadas pouco depois: 
É preciso racionalizar os dois lados. O povo pagará impostos e taxas com mais vontade se os vir bem aplicados, e rapidamente. E numa época de calamitosas enchentes, não deixará de pensar em como seria bom se completasse o cérebro eletrônico substituindo algumas de suas peças, como a que canta o hino nacional (...) por alguma outra capaz de acionar vassouras, desentupidores de bueiros e dragas, assim como equipes mecânicas para fechar buracos. Ah, seria tão bom, se fosse possível... (FSP, 17/02/1964)

O local escolhido para a instalação dos equipamentos também gerou controvérsia. Em 1963 o Parque do Ibirapuera se encontrava em situação bastante delicada. Criado em 1958 com o objetivo de abrigar museus e centros de cultura, no início da década de 1960 passou a receber órgãos da administração pública com utilização bem distante do projeto original. Entre os órgãos instalados, figuravam o "Pavilhão das Nações pelo gabinete do prefeito; Pavilhão dos Estados pelo sistema mecanizado e cérebro eletrônico da municipalidade; Pavilhão Verde pelo arquivo" (FSP, 1/04/63). A criação de uma fundação específica para a gestão do parque começou a ser discutida como forma de "assegurar a recuperação e a manutenção dos terrenos e dos edifícios desse logradouro publico que, dia a dia, vem sendo tomado pelo mato, tem suas alamedas em péssimo estado e não pode dar destino a vários pavilhões nele instalados" (FSP, 1/04/63). No ano seguinte, devidamente instalado no Pavilhão dos Estados, os problemas com os equipamentos foram ocasionados pelo racionamento de energia, decorrente da estiagem que reduziu a capacidade dos reservatórios da Light:

O cérebro eletrônico da Prefeitura, localizado no Pavilhão dos Estados (Ibirapuera) é quem mais tem sofrido os efeitos dos cortes de energia elétrica. Segundo o secretário de finanças, sr. Monteiro de Carvalho, os cortes de energia estão prejudicando o funcionamento do cérebro eletrônico exatamente no momento em que o equipamento está fazendo a expedição de um milhão de avisos do imposto predial, o que causa sérios prejuízos à prefeitura. Como consequência, estuda-se a instalação de um gerador próprio no local, a fim de evitar o 
Revista Brasileira de História \& Ciências Sociais - RBHCS

Vol. $8 \mathrm{~N}^{\mathrm{o}}$ 16, Julho - Dezembro de 2016

seccionamentos das atividades do cérebro eletrônico. (FSP, 24/01/1964 p.7)

Apesar dos custos elevados para aquisição, instalação e manutenção ainda assim, o interesse da administração publica se revelou crescente. O sistema aumentava a eficiência dos procedimentos, auxiliava na fiscalização contra fraudes, assegurava a expansão da base de contribuintes, além de aperfeiçoar a arrecadação, inclusive a cobrança de juros e tributos em atraso. Em consequência, os computadores eram vistos como elemento de primeiro porte para a modernização administrativa, como observamos no discurso do ministro Nei Galvão.

Ao lado de São Paulo, também o Rio de Janeiro buscou aumentar a arrecadação por meios eletrônicos. Desde 1939, o Rio de Janeiro procurava assegurar a mecanização desse procedimento ao criar o Serviço Mecanográfico da Secretaria de Finanças, composto por máquinas calculadoras de pequeno e médio porte e operando sobre uma receita de aproximadamente quatro milhões de cruzeiros. Vinte e quatro anos depois a receita da Secretaria de Finanças da Guanabara ultrapassava os 53 bilhões de cruzeiros e envolvia uma rede complexa, difícil de sustentar com maquinaria obsoleta.

Imagem 1: Carlos Lacerda em inauguração de computador IBM 1401 (página 11, terceiro parágrafo) 


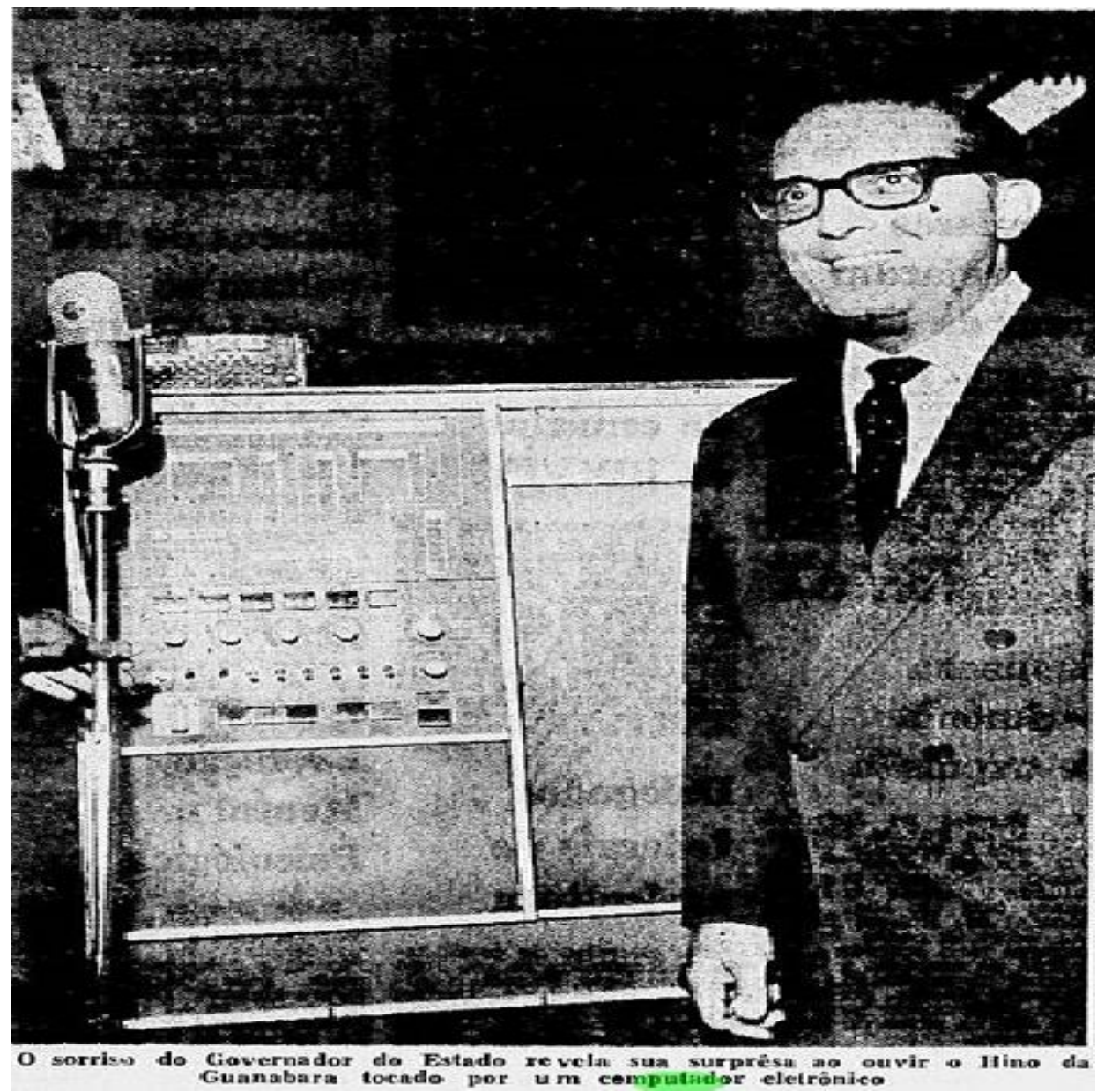

(Carlos Lacerda na cerimônia de inauguração do Centro de Processamento de Dados do Estado da Guanabara em março de 1963. O computador ao fundo é um IBM 1401. Créditos da foto: Correio da manhã, 12/o3/63, p.7).

No começo da década de 1960, a cidade do Rio de Janeiro, então Estado da Guanabara, importou dois modelos 1401 da IBM. Assim como os modelos de São Paulo, os equipamentos executavam os hinos dos respectivos estados e, ao mesmo tempo, potencializavam a capacidade de arrecadação, como indicava a imprensa da época: “ajudados pelo elemento humano poderão efetuar a emissão e arrecadação de impostos prediais, territoriais, de águas e esgotos, de indústrias e profissões, de localização e veículos, com uma economia de aproximadamente um terço”. (CDM, 12/03/63, p.7).

A verificação de que as duas principais cidades brasileiras foram, em conjunto, responsáveis pela introdução da informática na administração pública no país, entre 1961 e 1962, aporta para um elemento dissonante na interpretação de que esse processo teria sido comandado de forma centralizada pelo governo federal. Amparada por técnicos estrangeiros e por engenheiros brasileiros com especialização no exterior, a instalação dos equipamentos contribuiu para que, partir de 1962, 
começasse a se constituir um segmento profissional que passou a interagir e criar vínculos com as universidades brasileiras no campo do ensino e da pesquisa.

Ao mesmo tempo, a expansão da informática no setor privado, como será visto a seguir, contribuiu para que ensino, pesquisa e mercado de trabalho se interconectassem no processo de constituição de um novo segmento ao mesmo tempo econômico e técnico-científico.

\section{A expansão pelo mercado}

Apesar do interesse e dos investimentos realizados pela administração pública, os maiores importadores de computadores e equipamentos periféricos ao longo da década de 1960 foram indústrias e instituições financeiras, principalmente bancos. A expansão aconteceu não só por setores econômicos, mas também geograficamente, com aquisições verificadas em Minas Gerais e Rio Grande do Sul. Os principais modelos adquiridos foram IBM 1401 e RAMAC 305, com funções administrativas, gerenciais e processamento da folha de pagamento. Ao lado da aquisição, viável apenas para grandes corporações, um conjunto expressivo de médias e pequenas empresas alugava equipamentos de órgãos públicos ou contratava prestadoras de serviços na área de processamento de dados, eventualmente utilizando os escritórios locais dos fabricantes estrangeiros.

A expansão se dava também no plano internacional. Na América Latina, apenas o México possuía quantidade equivalente aos equipamentos existentes no Brasil, em parte devido à proximidade com os EUA, o que diminuía consideravelmente o custo do frete. No Cone Sul, a Argentina havia instalado em 1960 dois modelos UNIVAC I. No Chile, a primeira instalação ocorreu em 1961, na aduana de Valparaíso. Ainda sem legislação específica que regulamentasse as atividades, as importações brasileiras cresciam em ritmo constante. Às vésperas do golpe militar, havia cerca de 70 máquinas em operação no país com a estimativa de demanda reprimida em torno de 200 computadores, conforme levantamento do engenheiro Teodoro Oniga:

Em fins de 1963, o numero total de sistemas em funcionamento ou em vias de instalação no Brasil pode ser avaliado em cerca de 70, dos quais dois de grande porte (o do IBGE e o NCR-315 da Varig) e o resto 
de portes médio e pequeno, com predominância dos sistemas IBM (o tipo 1401 e o Ramac são frequentemente alugados). Os modelos 1401 e 1440 da IBM, Univac - 1004 (da Remington Rand), B-26o (da Burroughs), Gamma-30 da (Bull), NCR-315-B (da National Cash Register); são os principais competidores no mercado brasileiro cuja capacidade de absorção pode ser estimada num total de 200 computadores atualmente, o que deixa um déficit de 130 sistemas a serem instalados até 1965" (ONIGA, 1964).

O início da década de 1960 marcou também a consolidação da IBM como a principal fornecedora de equipamentos para o mercado em expansão. No plano internacional, a empresa já ocupava a maior fatia, tornando-se objeto das ironias que a denominavam como a "Branca de Neve" em meio aos "Sete Anões" (Cf. CORTADA, 1993). Em 1961, alguns elementos confirmariam sua hegemonia no mercado brasileiro, como apontado pelas tabelas apresentadas adiante. Para assegurar o controle do mercado, a IBM criou um Bureau disponibilizando um computador modelo 650, voltado para as pequenas e médias empresas. Aliás, é importante também ressaltar que nesse período algumas empresas passaram a montar computadores em suas sedes no Brasil, conforme Marques e Motoyama: "em 1961 a IBM já montava os primeiros computadores no país que a partir de 1964 passam a ser exportados; a empresa Burroughs inaugurava em São Paulo (Veleiros) a sua segunda planta industrial, fabricando (...) periféricos para computadores” (MARQUES \& MOTOYAMA, 1994, p.385).

$\mathrm{Na}$ tabela a seguir, encontra-se o detalhamento das importações brasileiras de computadores, entre 1957, com a chegada do primeiro UNIVAC 60, destinado ao Departamento de Águas e Esgotos de São Paulo (DAE-SP), até o início de 1964, no período que antecede o golpe militar ${ }^{8}$. As fontes para esse levantamento foram matérias jornalísticas, anúncios e propagandas publicadas nos jornais $O$ Estado de São Paulo, O Globo e Correio da Manhã, entre 1957 e 1964. Não se trata, evidentemente, de levantamento conclusivo, na medida em que seria impossível retraçar com precisão cada item importado. Porém, o detalhamento é

8 Mapeamento semelhante pode ser encontrado na dissertação de mestrado 'Evolução da computação no Brasil e sua relação com fatos internacionais', de Marilza de Loudes Cardi (Cf. CARDI, 2008, p, 58$59)$. 
Revista Brasileira de História \& Ciências Sociais - RBHCS

Vol. $8 \mathrm{~N}^{\mathrm{o}}$ 16, Julho - Dezembro de 2016

suficientemente minucioso para assegurar a compreensão da escala e da ordem de grandeza do objeto analisado.

Tabela 1: Computadores importados para o Brasil (página 13 terceiro parágrafo).

\begin{tabular}{|c|c|c|c|}
\hline Instituição/Empresa & Fabricante & Modelo & Ano9 \\
\hline DAE São Paulo & UNIVAC & UNIVAC 120 & 1957 \\
\hline Banco Francês Italiano & UNIVAC & UNIVAC 60 & 1958 \\
\hline Jóquei Clube São Paulo & UNIVAC & $\begin{array}{ll}\text { UNIVAC } & \text { File } \\
\text { Computer } & \end{array}$ & 1959 \\
\hline Anderson Clayton (SP) & IBM & RAMAC 305 & 1959 \\
\hline $\begin{array}{l}\text { Banco Hipotecário Lar } \\
\text { Brasileiro (RJ) }\end{array}$ & UNIVAC & UNIVAC 120 & 1960 \\
\hline PUC RJ & Burroughs & B-205 & 1960 \\
\hline IBGE & UNIVAC & 1005 & 1960 \\
\hline Varig & NCR & NCR 305 & 1960 \\
\hline Volkswagen & IBM & RAMAC 305 & 1960 \\
\hline Banco Sul-Americano & IBM & RAMAC 305 & 1960 \\
\hline Laborterápica Bristol & IBM & RAMAC 305 & 1960 \\
\hline Gessy & IBM & RAMAC 305 & 1960 \\
\hline IAPE (SP) & UNIVAC & UNIVAC 60 & 1960 \\
\hline Prefeitura de São Paulo & IBM & 1401 & 1960 \\
\hline Prefeitura de São Paulo & IBM & 1401 & 1960 \\
\hline Banco Mercantil (SP) & UNIVAC & UNIVAC 60 & 1960 \\
\hline General Electric (RJ) & IBM & RAMAC 305 & 1961 \\
\hline $\begin{array}{l}\text { Secretaria de Finanças } \\
\text { da Guanabara }\end{array}$ & IBM & 1401 & 1961 \\
\hline $\begin{array}{l}\text { Secretaria de Finanças } \\
\text { da Guanabara }\end{array}$ & IBM & 1401 & 1961 \\
\hline Rio Light & IBM & 1401 & 1961 \\
\hline Rio Light & IBM & 1401 & 1961 \\
\hline São Paulo Light & IBM & 1401 & 1961 \\
\hline São Paulo Light & IBM & 1401 & 1961 \\
\hline $\begin{array}{lr}\text { Montepio } & \text { dos } \\
\text { empregados do } & \text { Estado } \\
\text { da Guanabara } & \end{array}$ & IBM & 1401 & 1961 \\
\hline $\begin{array}{lrr}\text { Banco } & \text { Brasileiro } & \text { de } \\
\text { Descontos (Osasco) } & \end{array}$ & IBM & 1401 & 1961 \\
\hline Banco Boa Vista & IBM & 1401 & 1961 \\
\hline Esso & IBM & 1401 & 1961 \\
\hline $\begin{array}{lr}\text { Centro } & \text { de } \\
\text { Processamento de dados } \\
\text { da IBM (SP) }\end{array}$ & IBM & 1401 & 1961 \\
\hline $\begin{array}{lr}\text { Centro } & \text { de } \\
\text { Processamento de dados } \\
\text { da IBM (SP) }\end{array}$ & IBM & 650 & 1961 \\
\hline Speed (SP) & Bull & & 1961 \\
\hline
\end{tabular}

9 As fontes consultadas não permitem especificar a data de importação e de instalação. Considerou-se principalmente a data de instalação. 
Revista Brasileira de História \& Ciências Sociais - RBHCS

Vol. $8 \mathrm{~N}^{\mathrm{o}}$ 16, Julho - Dezembro de 2016

\begin{tabular}{|c|c|c|c|}
\hline USP & IBM & 1620 & 1961 \\
\hline DATAMEC (RJ) & IBM & 1401 & 1961 \\
\hline CIA Antártica Paulista & IBM & 1401 & 1961 \\
\hline $\begin{array}{lr}\text { SAMBRA } & \text { Fábrica de } \\
\text { Algodão } & \text { (Pres. } \\
\text { Prudente). } & \\
\end{array}$ & IBM & 1401 & 1961 \\
\hline Exposição Modas (RJ) & IBM & 1401 & 1961 \\
\hline Condoroil Tintas (RJ) & IBM & 1401 & 1962 \\
\hline $\begin{array}{lcc}\text { Banco } & \text { Nacional } & \text { de } \\
\text { Minas Gerais }(\mathrm{RJ})^{10} & \\
\end{array}$ & Burroughs & B-270 & 1962 \\
\hline $\begin{array}{ll}\text { Grupo Industrial } \\
\text { Pignatari (SP) }\end{array}$ & IBM & 1401 & 1962 \\
\hline $\begin{array}{l}\text { Banco do Estado do Rio } \\
\text { Grande do Sul }\end{array}$ & IBM & 1401 & 1962 \\
\hline $\begin{array}{l}\text { Companhia de seguros } \\
\text { de Minas Gerais (MG) }\end{array}$ & IBM & 1401 & 1962 \\
\hline $\begin{array}{l}\text { Companhia Municipal } \\
\text { de Transito (SP) }\end{array}$ & UNIVAC & UNIVAC 60 & 1962 \\
\hline Modas Clipper (SP) & IBM & 1401 & 1962 \\
\hline IBGE (RJ) & IBM & 1401 & 1962 \\
\hline $\begin{array}{lll}\text { Companhia } & \text { Docas } & \text { de } \\
\text { Santos (SP) } & & \\
\end{array}$ & Burroughs & B-280 & 1962 \\
\hline Banco Francês-Italiano & UNIVAC & 1004 & 1962 \\
\hline Máquinas Bull do Brasil & Bull & Gamma 30 & 1963 \\
\hline $\begin{array}{l}\text { Ministério da Fazenda } \\
\text { (SP) }\end{array}$ & UNIVAC & UNIVAC 120 & 1963 \\
\hline $\begin{array}{ll}\text { Caixa } & \text { Econômica } \\
\text { Federal } & \\
\end{array}$ & IBM & 1401 & 1963 \\
\hline $\begin{array}{l}\text { CIA Comércio } \quad \text { e } \\
\text { Navegação }\end{array}$ & IBM & 1401 & 1963 \\
\hline $\begin{array}{ll}\text { Banco } & \text { Português } \\
\text { Brasileiro } & \\
\end{array}$ & Burroughs & 1401 & 1963 \\
\hline Moinho Santista & IBM & 1401 & 1963 \\
\hline $\begin{array}{l}\text { Banco de Crédito Real } \\
\text { de Minas Gerais }\end{array}$ & IBM & 1401 & 1963 \\
\hline Pfizer (Guarulhos SP) & IBM & 1401 & 1962 \\
\hline $\begin{array}{l}\text { Johnson } \\
\text { (SJC) }\end{array}$ & IBM & 1401 & 1964 \\
\hline Walita & IBM & 1401 & 1964 \\
\hline $\begin{array}{ll}\text { S.A. } & \text { Indústrias } \\
\text { Matarazzo } & \\
\end{array}$ & IBM & 1401 & 1964 \\
\hline $\begin{array}{l}\text { Companhia Vale do Rio } \\
\text { Doce (ES) }\end{array}$ & IBM & 1401 & 1964 \\
\hline
\end{tabular}

A sistematização dos dados acima aponta alguns elementos relevantes para análise. Inicialmente, a expansão de aquisições a partir de 1960 e a predominância da IBM nesse processo. Em 1961, por exemplo, foram instaladas 19 máquinas, todas

${ }^{10}$ Embora tenha sido comprado pelo Banco Nacional de Minas Gerais, com sede em Belo Horizonte, o B-270 foi instalado na filial da Guanabara. 
IBM. A diversidade dos usuários é igualmente relevante, dado o porte e a inserção social, política econômica. De um lado setores estratégicos do governo, em diferentes níveis da administração pública ou prestadoras de serviços públicos. De outro, setores corporativos, como bancos e indústrias de grande porte. Apesar da predominância da IBM, ainda assim, estiverem presentes outros grandes fornecedores como Remington, Burroughs, NCR e Bull.

Os dados apurados permitem identificar também os segmentos econômicos que primeiro se informatizaram no país, basicamente os setores secundário (indústrias) e o terciário, (comércio e bancos). De início, o setor comercial importou menos do que bancos e indústrias, dado o alto custo de aquisição e manutenção, restringindo o processo aos segmentos mais capitalizados.

Na década de 1950 apenas a Anderson Clayton contava com um RAMAC 305. A partir de 1961, a criação de prestadoras de serviços, como a Serviço de Processamento Eletrônico de Dados (SPEED), ORGAMEC e da DATAMEC permitiram que pequenas e médias empresas se valessem do sistema de consignação e repartissem os custos levados. Assim, determinado percentual de horas era contratado mensalmente para serviços como de folha de pagamento e balanços financeiros. O rateio de horas foi utilizado também no setor público. Em 1962, por exemplo, os Ministérios da Fazenda. Educação e Cultura, Trabalho e Previdência, Prefeituras de Porto Alegre e Florianópolis, Banco do Brasil, publicaram edital de licitação com a mesma finalidade (DOU, 18/10/1962). A ORGAMEC venceu a licitação e, pelo mesmo sistema, atendeu mais de 20 órgãos públicos e empresas, entre as quais a Coca-Cola do Brasil e a Minasgás.

A expansão do mercado alcançou o comercio varejista e, em 1965, lojas de departamento domo Modas Clipper e Mesbla adquiriram computadores, modelo 1401, para atividades administrativas e realização de eventos como a Exposição Moda. Nos demais ramos, outros modelos foram ganhando espaço, como o IBM RAMAC 305, adquirido por empresas como General Electric do Brasil e Volkswagen, destinados ao controle de estoques, produtos, fornecimento e folhas de pagamento. (O GLOBO, 09/07/61, p. 4).

\section{Mercado diversificado e um novo "imaginário" estatístico}


As prestadoras de serviços de processamento de dados também passaram a organizar, com frequência, rodadas de "Jogos de Empresas", a partir dos dados estatísticos produzidos pelo novo maquinário, envolvendo o mercado nacional e internacional. As fórmulas matemáticas permitiam criar cenários e simulações, em um ambiente controlado, a partir do qual no qual as decisões de determinado grupo alteravam o contexto. Uma nova ferramenta de gestão de empresas começava a ser testada por aquela que se tornaria uma das referências na formação de executivos, a Fundação Getúlio Vargas (FGV).

O primeiro jogo nesses moldes aconteceu em 1962, organizado pela FGV em associação com a SPEED, que cedeu o computador Gamma Bull. Em 1963, Marco Antônio Filippi descreveu os "Jogos" como "nova técnica de treinamento, originária da França, destina-se à análise da evolução econômica de mercados de matériasprimas e de produtos em relação à política de gestão das empresas em concorrência (...). O conjunto dessas fórmulas constitui um modelo hipotético de mercado, capaz de reagir a fatos também hipotéticos, de maneira semelhante a que um mercado real reagiria a uma decisão real" (FILIPPI, 30/04/1963, p.9).

O jogo era realizado em turnos de uma hora. Cada grupo representava uma empresa fictícia e precisava tomar decisões administrativas (aumento de produção, corte nas despesas de pessoal, promoções publicitárias, retração) em 45 minutos. Em 15 minutos o computador projetava os efeitos das decisões no cenário geral simulado. O uso de computadores para simulações também se tornou comum nas Forças Armadas, que realizavam "jogos de guerra” e simulações de combate.

\section{Considerações Finais}

A expansão da informática no país a partir do final da década de 1950 se acentuou entre 1960 e 1964, o que ocorreu tanto pela diversificação entre as diferentes esferas dos segmentos públicos e nos setores privados, como também em sua base geográfica. A despeito da previsível concentração no eixo Rio-São Paulo, a nova tecnologia se disseminou inicialmente pelos estados de Minas Gerais, Rio Grande do Sul e Espírito Santo, na então recente capital federal, Brasília, como tiveram também no Paraná e Pernambuco a partir de 1965. 
Até o advento do golpe militar de 1964, o país somava cerca de 80 computadores instalados e em funcionamento, e dispunha de uma série de contratos para novas instalações. Ao mesmo tempo em que crescia a aquisição, instalação e uso dos computadores no país também, aumentava rapidamente os serviços e os usuários no país. Apesar da expansão do mercado desde o final do governo de Juscelino Kubitschek, as políticas públicas para o setor não acompanharam esse crescimento. Algumas hipóteses podem ser formuladas, entre as quais o alto custo de aquisição, instalação e manutenção dos equipamentos, além de entraves burocráticos na liberação das importações. Igualmente impeditiva, foi a ruidosa oposição parlamentar, capitaneada pelo partido da União Democrática nacional (UDN). Por fim, um conjunto de polêmicas e acusações que envolveram a aquisição de equipamentos para o IBGE polarizou o debate sobre a importação de computadores.

\section{Fontes}

\section{Jornais (inclusos os artigos utilizados na produção da tabela 1):}

"Revolução silenciosa no reino dos sabonetes" in O Globo, 23 de junho de 1960, Geral, p.15.

"O Brasil será padrão para a América Latina" in O Globo, 16 de agosto de 1960, Geral, p.12.

"Administração eletrônica em São Paulo" in O Globo, 20 de agosto de 1960, Geral, p5. "Métodos eletrônicos na indústria farmacêutica" in O Globo, 11 de outubro de 1960 p.3.

"Computador eletrônico para o IPESP" in O Estado de São Paulo, 30 de dezembro de 1960, Primeiro Caderno, p.10.

"O cérebro de um Banco no sossego de Osasco" in O Globo, o6 de março de 1961, Geral, p9.

"Computadores eletrônicos a serviço também de firmas pequenas e médias" in $\mathrm{O}$ Globo, 27 de abril de 1961, Geral, p.

"Métodos eletrônicos na Administração da Esso" in Correio da Manhã, 28 de maio de 1961, p10.

"60 milhões de lâmpadas para as noites do Brasil" in O Globo, o9 de julho de 1961, Geral, p4.

"Computador eletrônico para a iniciativa privada" in O Globo, 24 de novembro de 1961, Geral, p4.

"Chegou a SP cérebro eletrônico" in Correio da Manhã, 03 de dezembro de 1961, p.7.

"Computadores eletrônicos IBM conduzem à reformulação dos métodos administrativos" in Correio da Manhã, 18 de janeiro de 1962, Primeiro Caderno, p.11. "Dois computadores eletrônicos inauguram novos métodos administrativos na prefeitura de São Paulo" in O Globo, 25 de janeiro de 1962, Geral, p.12. 
FILIPPI, Marco Antônio. "A simulação no uso do computador eletrônico" in O Estado de São Paulo, São Paulo, 30 de abril de 1962, Suplemento Comercial e Industrial, p.9. "Correio militar" in Correio da Manhã, o4 de maio de 1962, Segundo Caderno, p.6.

"Grupo industrial Pignatari adota administração eletrônica" in O Globo, 18 de maio de 1962, Geral, p.13.

"Aceleram-se no Banco do Estado do Rio Grande do Sul os trabalhos para a implantação do computador IBM 1401" in O Globo, 29 de agosto de 1962, p. 4.

"Computador eletrônico será instalado em Banco do Rio" in O Globo, 25 de julho de 1962, Geral, p.4.

"Brasil lidera a automação bancária no continente" propaganda da Burroughs publicada em Correio da Manhã, 22 de julho de 1962, Primeiro Caderno, p5.

"Pioneira em Minas Gerais: CIA. de seguros Minas-Brasil vai instalar computador eletrônico IBM" in Correio da Manhã, 19 de setembro de 1962, Geral, p.7.

"Modas a Exposição-Clipper vai reformular seus métodos administrativos: contratou vinda de um computador eletrônico" in O Globo, 27 de setembro de 1962, Geral, p.9. "Computador Burroughs leva automação eletrônica ao porto de Santos" in O Globo, 18 de novembro de 1962, Geral, p.16.

"Computador Remington 'UNIVAC' é adquirido pelo Banco Francês e Italiano" in O Globo, 02 de novembro de 1962, Geral, p.2.

"Serviço mecanográfico da secretaria de Finanças adota computação eletrônica" in Correio da Manhã, 13 de março de 1963, Primeiro Caderno, p.7.

"O Ibirapuera não desaponta a cidade: é também esburacado" in Folha de São Paulo, primeiro de abril de 1963, Ilustrada, p.1.

"A CIA. Comércio e Navegação adota computador eletrônico IBM 1401" in O Globo, 25 de abril de 1963, Geral, p.13.

"Um banco em expansão" in O Globo, 21 de maio de 1963, Geral, p.16.

"A Pfizer Corporation do Brasil adota a computação eletrônica" in Correio da Manhã, 18 de junho de 1963, Primeiro Caderno, p.9.

"Importação do Sistema Eletrônico na Caixa Econômica Federal do Rio de Janeiro" in Correio da Manhã, 27 de julho de 1963, p.8.

"Banco Português do Brasil e Burroughs pioneiros na América do Sul" in Correio da Manhã, 28 de julho de 1963, segundo caderno, p.15.

"S/A Moinho Santista Indústrias Gerais" in O Globo, 22 de outubro de 1963, Geral, p.16.

"Johnson e Johnson Acompanha o progresso utilizando a computação eletrônica" in O Globo, 28 de janeiro de 1964, Geral, p.11.

"Walita adota o mais novo conceito em computação eletrônica IBM 1440" in Correio da Manhã, 04 de fevereiro de 1964, p.8.

"CIA. VALE DO RIO DOCE" in JORNAL DO BRASIL, Rio de Janeiro, 20 de março de 1964.

"S.A. Indústrias Matarazzo: Relatório da diretoria" in O Estado de São Paulo, 21 de abril de 1964, p.10.

ONIGA, Teodoro. "O Brasil na era dos computadores" in Jornal do Brasil, 22 de janeiro de 1964.

"A escola de sociologia da PUC usa o cérebro eletrônico para pesquisa de opinião pública" in O GLOBO, 03 de outubro de 1964, Geral, p.7.

\section{Bibliografia}

BRETON, Phillipe. História da informática. São Paulo, Editora da Universidade Estadual Paulista, 1991. 
EVANS, PETER. Embedded Autonomy: States and Industrial Transformation. New Jersey, Princeton University Press, 1995.

MINISTÉRIO DA FAZENDA. História do imposto de renda. Brasília, 2010. Disponível

http://www.receita.fazenda.gov.br/Memoria/irpf/historia/historia.asp. Acessado em 16/03/2015

MARQUES, Paulo; MOTOYAMA, Shozo. "Informática no Brasil. Apontamentos para o estudo" in VARGAS, Milton (Org.). História da técnica e da tecnologia no Brasil. São Paulo, Editora UNESP, 1994, p.375-398 